\title{
Percurso histórico-epistemológico dos estudos de citação no Brasil
}

\author{
Historical and epistemological trajectory \\ of the citation studies in Brazil
}

\author{
Murilo Artur Araújo da SILVEIRA' \\ Sônia Elisa CAREGNATO²
}

\section{Resumo}

Este artigo apresenta a trajetória histórica e epistemológica dos estudos de citação no Brasil por meio dos artigos de periódicos nacionais. Tem como justificativa a ausência de pesquisas que apontem o estado da arte dos estudos de citação no Brasil, bem como a importância dos seus resultados para a compreensão da dinâmica dos contextos de produção e comunicação da ciência. O objetivo da pesquisa é identificar e discutir os elementos que configuram a trajetória histórica e epistemológica dos estudos de citação no Brasil presentes nos artigos indexados na Base de Dados Referencial de Artigos de Periódicos em Ciência da Informação, de 1972 a 2014. A pesquisa, de natureza descritiva, utilizou a técnica de análise de conteúdo para sistematização temporal e teórico-metodológica dos elementos constantes dos artigos publicados ao longo de quarenta anos. Discute as características e as configurações dos estudos de citação com base: (a) nos dois períodos: embrionário e emergente; e (b) nos enfoques teóricos: normativo, construtivista e sociocultural. Sinaliza o estágio do percurso histórico e epistemológico dos estudos de citação e lança perspectivas para os próximos trabalhos relacionados à temática.

Palavras-chave: Análise de citação. Brasil. Epistemologia. História.

\begin{abstract}
The paper presents the historical and epistemological trajectory of citation studies in Brazil through national scientific journal articles. It is justified by the lack of studies that show the state of the art of citation studies in Brazil, as well as the importance of their results for the understanding of the contexts of production and communication of science. The objective of the research is to identify and discuss the elements of the historical and epistemological trajectory of citation studies in Brazil in articles indexed on the Base de Dados Referencial de Artigos de Periódicos em Ciência da Informação, 1972-2014. The research work has a descriptive nature and uses content analysis techniques to systematize temporal, theoretical and methodological information contained in articles published over forty years. It discuss the features and settings of citation studies based on: (a) two stages: embryonic and emerging; (b) the theoretical approaches: normative, constructive and sociocultural. It shows the stage of historical and epistemological trajectory of citation studies and launches prospects for future work related to the thematic.
\end{abstract}

Keywords: Citation analysis. Brazil. Epistemology. History.

\section{Introdução}

A realização de estudos de citação, no âmbito da Comunicação Científica, acontece por meio de investi- gações teóricas e aplicadas, sendo as últimas as mais encontradas na literatura especializada. Esses estudos têm como objeto as citações e as referências, em suas perspectivas objetivas e subjetivas, registradas nos textos

\footnotetext{
1 Universidade Federal de Pernambuco, Centro de Artes e Comunicação, Departamento de Ciência da Informação. Av. da Arquitetura, s/n., Cidade Universitária, 50740-550, Recife, PE, Brasil. Correspondência para/Correspondenceto: M.A.A. SILVEIRA.E-mail:<muriloas@gmail.com>.

2 Universidade Federal do Rio Grande do Sul, Departamento de Ciência da Informação, Programa de Pós-Graduação em Comunicação e Informação. Porto Alegre, RS, Brasil.

Recebido em 16/12/2015, reapresentado em 20/6/2016 e aprovado para publicação em 15/8/2016.
} 
científicos para fins de avaliação das atividades e práticas de produção, comunicação e uso do conhecimento. Os resultados advêm, primordialmente, da utilização de técnicas bibliométricas, isoladamente ou em conjunto, com outras técnicas de ordem quantitativa ou qualitativa, amparados em repertórios teóricos e epistemológicos de campos e domínios específicos, a exemplo da Sociologia da Ciência e da Filosofia da Ciência, dentre outros (WOUTERS, 1999).

A aproximação dos estudos de citação com a Ciência da Informação é percebida por meio do interesse pelas formas e possibilidades de produção e uso da informação científica e tecnológica e os reflexos oriundos dessa relação, baseados na dinâmica das práticas que governam o universo científico. Ao mesmo tempo que gozam de prestígio no universo da ciência por oferecerem indicadores de produção, colaboração e relação do fazer científico, os estudos de citação também são questionados negativamente, na medida em que representam um quadro parcial da realidade (GLANZEL, 2003). As críticas sempre pontuam a orientação quantitativa e superficial que os trabalhos imprimem em sua concepção e apresentação, em detrimento de análises mais aprofundadas e qualitativas (BORNMANN; DANIEL, 2008; ERIKSON; ERLANDSON, 2014).

As atenções dos estudos de citação, via de regra, voltam-se para o conhecimento de realidades científicas, necessitando que os estudiosos sobre o tema empreendam esforços maiores para a realização de estudos que demonstrem o estágio de institucionalização alcançado. A reivindicação é feita para que se apontem os caminhos teóricos, metodológicos, instrumentais e sociais percorridos por essas pesquisas, buscando a garantia de seus efeitos e suas contribuições científicas para o domínio da Comunicação Científica e da Ciência da Informação. Por conta do cenário de possibilidades, limitações e controvérsias que se reivindicam, admite-se que a configuração teórico-metodológica dos estudos de citação pode ser verificada por três importantes enfoques: normativo, construtivista e sociocultural. A sugestão desses modelos teóricos, amplamente discutidos na tese de doutorado defendida em 2016, considera a não exclusividade dos enfoques, partindo do pressuposto de que eles são complementares.

Fundamenta o enfoque normativo a ideia de que a ciência é uma instituição normativa, governada pelo reconhecimento de dívidas intelectuais e sanções internas promovidas pelas citações e referências, com base nos preceitos mertonianos (NICOLAISEN, 2007). Já o enfoque construtivista reconhece que o ato de citar é resultante de mudanças cognitivas e envolvido por aspectos complexos e multivariados que influenciam as razões dos cientistas em suas citações (BORNMANN; DANIEL, 2008; ERIKSON; ERLANDSON, 2014). Por fim, a base do enfoque sociocultural está no efeito das citações e nas consequências decorrentes dos contextos culturais das comunidades científicas, em especial as filiações teóricas e mercantis da produção de conhecimento (DAVIS, 2009; ERIKSON; ERLANDSON, 2014).

Diante da pluralidade e vitalidade dos estudos de citação, como também da diversidade das ênfases das pesquisas realizadas, questiona-se: (a) qual o quadro geral dos estudos de citação publicados nos periódicos brasileiros? (b) qual a configuração epistemológica dos estudos de citação no Brasil? e (c) quais as características da produção brasileira na temática dos estudos de citação?

Esses questionamentos conduzem esta contribuição, com o propósito de investigar o percurso histórico-epistemológico dos estudos de citação, sendo parte integrante de uma pesquisa de doutorado. Nesses termos, o objetivo central deste estudo é identificar e discutir os elementos que configuram a trajetória histórica e epistemológica dos estudos de citação no Brasil, presentes nos artigos disponíveis na Base de Dados Referencial de Artigos de Periódicos em Ciência da Informação (BRAPCI) de 1972 a 2014.

Tal conhecimento possibilitará aos pesquisadores estabelecer os marcos epistemológicos que orientam as pesquisas e ainda determinar como e quais as áreas temáticas que se beneficiaram, de alguma forma, com os resultados lançados. Nesses termos, são duas as justificativas deste trabalho: (a) científica: direcionada para a exibição do estágio epistemológico consolidado nas publicações, alcançado pela dinâmica instaurada e conduzida pelos autores nas formas de discussão teórica, descrição metodológica e apresentação de resultados ao longo dos anos no escopo da temática; e (b) histórica: voltada para o detalhamento dos caminhos trilhados pelos pesquisadores e que necessitam ser explorados, 
reorganizados e analisados, de forma a ilustrar a linhagem histórica desses estudos e suas contribuições efetivas.

\section{Procedimentos metodológicos}

O trabalho consistiu na análise de conteúdo dos artigos recuperados na Brapci em maio de 2015 sobre o tema estudos de citações. Os termos que guiaram a busca na Brapci foram: citação, citações, análise de citação, análise de citações, estudos de citação, estudos de citações, referências, análise de referências e estudos de referências no campo principal, com a seleção todos os campos. As respostas por cada palavra-chave trouxeram arquivos diversos, necessitando de seleção atenta para eliminar os itens sobrepostos e não relacionados ao escopo da busca, totalizando 154 artigos publicados de 1972 a 2014.

Após cuidadosa seleção dos trabalhos, por meio da leitura dos títulos, resumos e palavras-chave (e em alguns casos, o artigo na íntegra), que se configuravam como estudos de citação, chegou-se ao número de 106 itens. Convém esclarecer que a noção que norteou o entendimento sobre estudos de citação está baseada em trabalhos e pesquisas em que as citações e as referências foram os objetos empíricos de análise, com o propósito de evidenciar as configurações dos fluxos da informação registrada e respaldados por aportes teóricos e metodológicos de natureza científica.

Após a captura de todos os artigos referentes ao tema, os elementos descritivos foram tabulados em uma planilha do Microsoft Excel para manipulação dos dados e apresentação dos resultados. Os elementos descritivos contemplados para a realização do trabalho foram: ano de publicação, autores dos artigos, título do artigo, resumo do artigo, título do periódico, enfoque teórico do artigo, descrição metodológica, softwares utilizados, resultados obtidos, campos e/ou domínios de aplicação e análise crítica do artigo.

Para a organização dos dados referentes ao trajeto histórico e epistemológico dos estudos analisados, foi realizada a categorização dos 106 trabalhos por ano de publicação, para verificar o processo evolutivo e as características de publicação. Com base nas marcas históricas e de produção, a análise dos trabalhos foi conduzida por meio da categorização em dois momentos para evidenciar os percursos das pesquisas ao longo do tempo. Quanto à categorização dos trabalhos com relação aos enfoques teóricos, é oportuno esclarecer que foram considerados: a discussão teórico-conceitual, os objetivos estabelecidos, os objetos analisados e, por fim, os resultados descritos.

\section{Os estudos de citação no Brasil}

Do conjunto de textos analisados, registra-se a predominância de trabalhos com foco no objeto empírico (citações e referências), configurando-se, de forma exclusiva, como estudos de citação, com 78 artigos. Os outros trabalhos (28 artigos) se configuram como estudos de citação, contemplados como uma das facetas de análises bibliométricas, sempre de forma complementar. É necessário observar que o caráter exclusivo dos estudos de citação foi percebido nas primeiras contribuições científicas, sobretudo nas décadas de 1970, 1980 e 1990, mantendo o mesmo nível nas décadas subsequentes. Contudo, nas décadas de 2000 e 2010, os trabalhos com enfoque complementar ocorrem com mais frequência, mas não acompanham o ritmo dos estudos exclusivos. Acredita-se que o panorama descrito pode ser explicado pela presença das tecnologias da informação no desenvolvimento das pesquisas, o que potencializou a coleta e manipulação dos dados e as formas de apresentação dos resultados. Outra hipótese para a situação é o intercâmbio de métodos, técnicas e instrumentos de pesquisa, aliado ao surgimento e aprimoramento de bases de dados e softwares aplicáveis aos estudos de citação.

Outro destaque em relação aos artigos analisados é que 99 deles foram originados de pesquisas e comunicados na seção de artigos dos periódicos cobertos pela Brapci. Parte significativa da produção das décadas de 1970 e 1980 foi oriunda de dissertações do Curso de Mestrado em Ciência da Informação do Instituto Brasileiro de Ciência e Tecnologia (lbict), conforme indicação nas notas de rodapé e/ou na introdução dos artigos. As publicações dos anos 1990 são marcadas por contribuições pontuais, de um grupo restrito de professores e pesquisadores já formados e familiarizados com o emprego da técnica de análise de citações. Nas décadas seguintes (2000 e 2010), o número das pesquisas aumen- 
ta, significativamente, em especial as relacionadas aos resultados de dissertações e teses defendidas nos programas de pós-graduação em Ciência da Informação do país, com base nas indicações apresentadas pelos autores nos textos analisados.

Sobre a produção científica publicada ao longo dos anos, o Figura 1 apresenta a distribuição no período de 1972 a 2014 sobre o tema nos principais periódicos brasileiros.

A representação gráfica demonstra um percurso dos estudos de citação no Brasil presentes na base Brapci, com a sinalização de dois períodos distintos que marcam a trajetória das pesquisas e dos relatos. Devido às características dos momentos desses estudos, sugere-se a demarcação dos trabalhos por períodos e momentos conforme o Quadro 1.
A Figura 1 sinaliza períodos de tempo que demarcam um percurso de instabilidade, resistência e vigor das pesquisas, confundindo-se com a trajetória dos estudos métricos da informação, conforme indicam Barreto e Miranda (2000): o período denominado "época das leis", em referência às leis bibliométricas, teve seu auge nos anos 1970 e 1980, em decorrência da presença de pesquisadores estrangeiros quando da instalação do Curso de Mestrado em Ciência da Informação do Ibict, perdendo o fôlego nas décadas seguintes. A retomada das discussões sobre esses temas (incluindo aqui os estudos de citação) acontece com a publicação do volume especial da revista Ciência da Informação de 1998, impulsionada pelo surgimento do Projeto Scientific Eletronic Library Online (SciELO). Diante do quadro exposto, indaga-se: quais as perspectivas futuras para os

Quadro 1. Períodos e momentos dos estudos de citação.

\begin{tabular}{llll}
\hline Período & \multicolumn{2}{c}{ Período embrionário } & Período emergente \\
\hline Momentos & \multicolumn{1}{c}{ Primeiro momento } & \multicolumn{1}{c}{ Segundo momento } & 2006-dias atuais \\
\hline Cronologia & $1973-1981$ & $1982-2005$ & Início do crescimento acentuado do \\
Descrição & Início dos primeiros estudos e o & Retomada das pesquisas e manu- & número de pesquisas, marcado por \\
& momento do primeiro declínio. & $\begin{array}{l}\text { tença do volume mínimo de } \\
\text { publicação. }\end{array}$ & oscilações. \\
\hline
\end{tabular}

Fonte: Dados da pesquisa (2015).

Quadro 2. Autores mais produtivos na temática estudos de citação.

\begin{tabular}{|c|c|c|c|}
\hline Autores & $\sum$ & Autores & $\sum$ \\
\hline Ely Francina Tannuri de Oliveira ${ }^{* 1}$ & 8 & Admar Costa de Oliveira & 2 \\
\hline Maria Cláudia Cabrini Grácio*1 & 8 & Bruna Silva do Nascimento* & 2 \\
\hline Murilo Artur Araújo da Silveira* & 7 & Daisy Pires Noronha* & 2 \\
\hline Carlos Alberto Ávila Araújo* & 5 & Edna Lúcia da Silva* & 2 \\
\hline Ida Regina Chittó Stump**1 & 4 & Fábio Mascarenhas e Silva* & 2 \\
\hline Leilah Santiago Bufrem* & 4 & Gustavo Liberatore* & 2 \\
\hline Adilson Luiz Pinto ${ }^{*}$ & 3 & Jacques Wainer* & 2 \\
\hline Ana Maria Mattos & 3 & José Garrofe Dórea & 2 \\
\hline Beatriz Valadares Cendón*1 & 3 & Juliana Lazzarotto Freitas & 2 \\
\hline Ivone Job & 3 & Liliane Vieira Pinheiro & 2 \\
\hline Lídia Alvarenga* & 3 & Maria Lourdes Blatt Ohira* & 2 \\
\hline Maria de Jesus Nascimento* & 3 & Mohammad Hossein Biglu* & 2 \\
\hline Maria de Lourdes Borges de Carvalho & 3 & Paula Vanessa Medeiros Vieira & 2 \\
\hline Rogério Eduardo Rodrigues Bazi* & 3 & Raimundo Nonato Macedo dos Santos ${ }^{* 1}$ & 2 \\
\hline Samile Andréa de Souza Vanz & 3 & Rubén Urbizagástegui Alvarado* & 2 \\
\hline Sônia Domingues Santos Brambilla & 3 & Semíramis Martins Alvares Domene* & 2 \\
\hline Sônia Elisa Caregnato ${ }^{* 1}$ & 3 & Suzana Pinheiro Machado Mueller ${ }^{* 1}$ & 2 \\
\hline
\end{tabular}

Nota: *Docentes; ${ }^{* 1}$ Bolsistas de Produtividade em Pesquisa do Conselho Nacional de Desenvolvimemto Científico e Tecnológico.

Fonte: Dados da pesquisa (2015). 


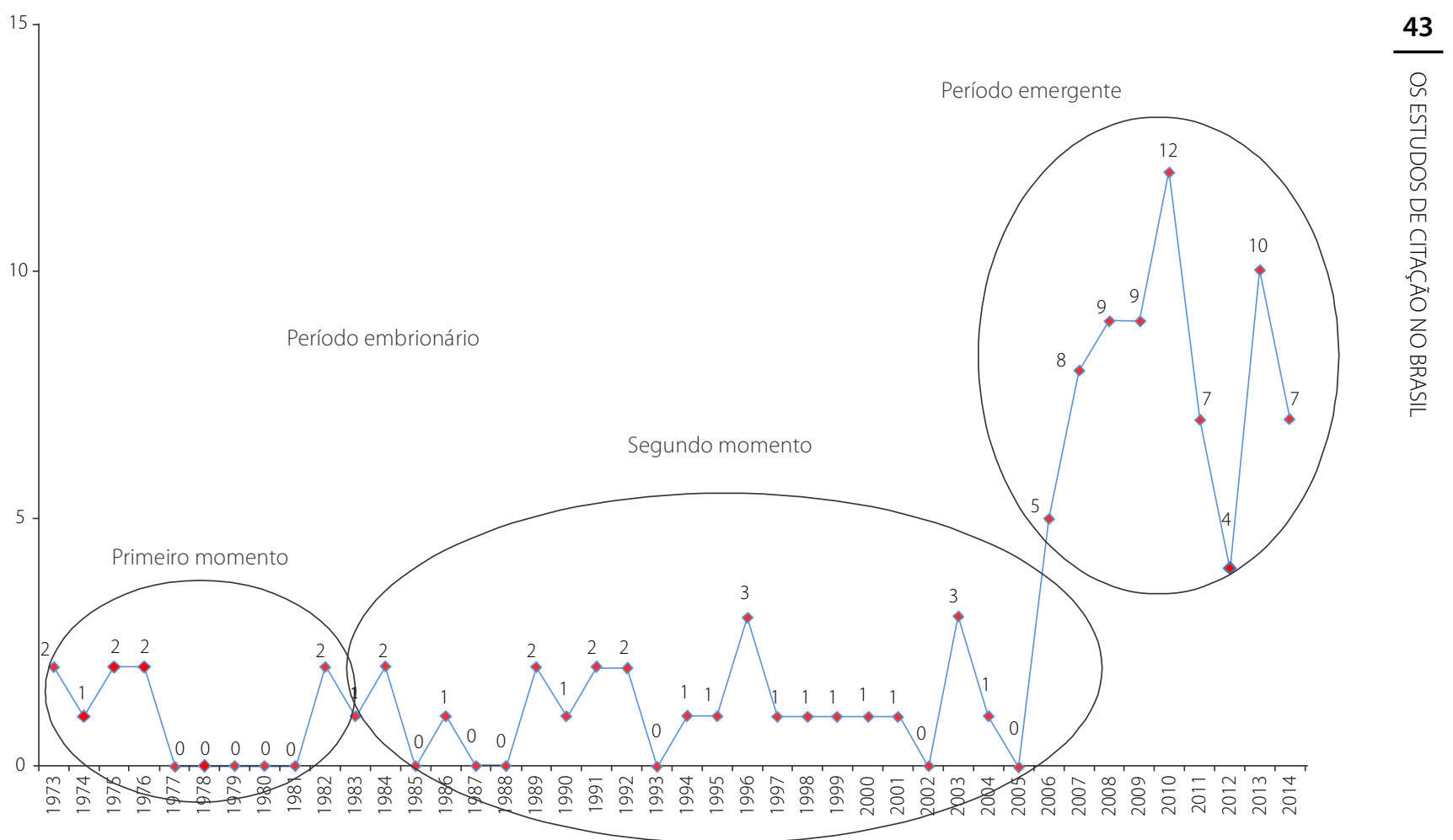

Figura 1. Distribuição temporal dos estudos de citação por ano. Fonte: Dados da pesquisa (2015).

estudos de citação quanto ao volume de publicações nos veículos especializados?

Em relação à autoria dos trabalhos que versam sobre os estudos de citação, o Quadro 2 exibe os autores mais profícuos ao longo de 40 anos.

Do conjunto de autores que publicaram sobre o tema, 45\% publicaram dois artigos no mínimo, constituindo-se o grupo dos mais produtivos. Entre os 34 autores, 26 exerciam a docência quando da publicação ${ }^{*}{ }^{*}$, quase todos em instituições públicas de ensino superior; e oito desses docentes eram bolsistas de produtividade em pesquisa do Conselho Nacional de Desenvolvimento Cientifico e Tecnológico (CNPq) (destacados em negrito), à época, expressando assim a qualificação profissional dos autores. Dos pesquisadores presentes no Quadro 2, três são estrangeiros (Gustavo Liberatore, Mohammad Hossein Biglu e Rubén Urbizagástegui Alvarado), cinco são autores brasileiros de outros campos científicos (Admar Costa de Oliveira, Jacques Wainer, José Garrofe Dórea, Paula Vanessa
Medeiros Vieira e Semíramis Martins Alvares Domene) e quatro são bibliotecárias (Ana Maria Mattos, Ivone Job, Sônia Domingues Santos Brambilla e Liliane Vieira Pinheiro).

Do ponto de vista institucional, a autoria se concentra em instituições das regiões Sudeste e Sul, com destaque para Universidade Federal do Rio Grande do Sul (6), Universidade Estadual Paulista (3), Universidade Federal de Minas Gerais (3), Universidade Federal de Santa Catarina (3), Universidade do Estado de Santa Catarina (2) e Universidade Estadual de Campinas (2) e fora desse eixo regional do país, a Universidade Federal de Pernambuco é a instituição que se sobressai com 4 professores. Nota-se ainda a presença das seguintes instituições: Universidade Federal de São Paulo, Universidade de São Paulo (USP), Pontifícia Universidade Católica de Campinas (PUC-Campinas) e Universidade Federal do Estado do Rio de Janeiro.

A produção científica publicada pelos autores presentes no Figura 2 se concentra nas décadas de 2000 e 2010, em especial nesta última, que apresentou o maior 
número de publicações sobre a temática, resultante da ampliação qualificada de recursos humanos nas instituições de ensino superior, bem como do aumento do financiamento de pesquisas e do incremento no número de vagas na pós-graduação. É necessário apontar que, além do contexto científico favorável, muitos dos autores listados têm vasta experiência no desenvolvimento de pesquisas e orientações nos domínios da Comunicação Científica e dos Estudos Métricos, viabilizando o aumento da produção e ainda a formação de nova massa crítica para os anos e as décadas seguintes.

Por outra ótica de análise, a percepção da produção dos autores mais produtivos está focada na intersecção dos domínios da Comunicação Científica e dos Estudos Métricos, estando os estudos de citação em uma posição privilegiada. No processo de consulta à produção global dos pesquisadores destacados, verifica-se que os interesses de pesquisas estão direcionados para estudos de produção, organização e comunicação da informação científica, de formulação e análise de indicadores em Ciência, Tecnologia e Informação (CT\&l), levando às seguintes indagações: estão os estudos de citação entre as preocupações desses pesquisadores? Em que níveis de relevância? Em que contextos de pesquisa?
Acredita-se que as respostas a tais questões possam definir não somente o núcleo principal de pesquisadores na temática, mas também sinalizar os rumos para os próximos anos.

Ainda sobre a discussão dos autores mais produtivos, é oportuno retornar aos trabalhos de Oliveira e Grácio (2011a) e Silveira et al. (2013) sobre o domínio que envolve os estudos de citação representado pelo Grupo de Trabalho (GT) 7 do Encontro Nacional de Pesquisa em Ciência da Informação (Enancib) por elencarem os autores mais produtivos e os mais citados nas comunicações do encontro. Desse conjunto de autores (produtores e citados), muitos dos pesquisadores encontram-se listados no Quadro 2 em especial os mais experientes, por serem os orientadores dos futuros pesquisadores e por terem publicado as bases teórico-metodológicas que fundamentam boa parte dos estudos realizados. Surgem assim duas questões: os autores presentes no Quadro 2 fundamenta a enfoque normativo. São, ao mesmo tempo, produtores de artigos e citados nos trabalhos sobre estudos de citação? Quais as circunstâncias e os contextos de citação desses autores no processo de produção de um trabalho?

Em continuidade à discussão, quanto aos veículos disseminadores da produção científica sobre os estudos

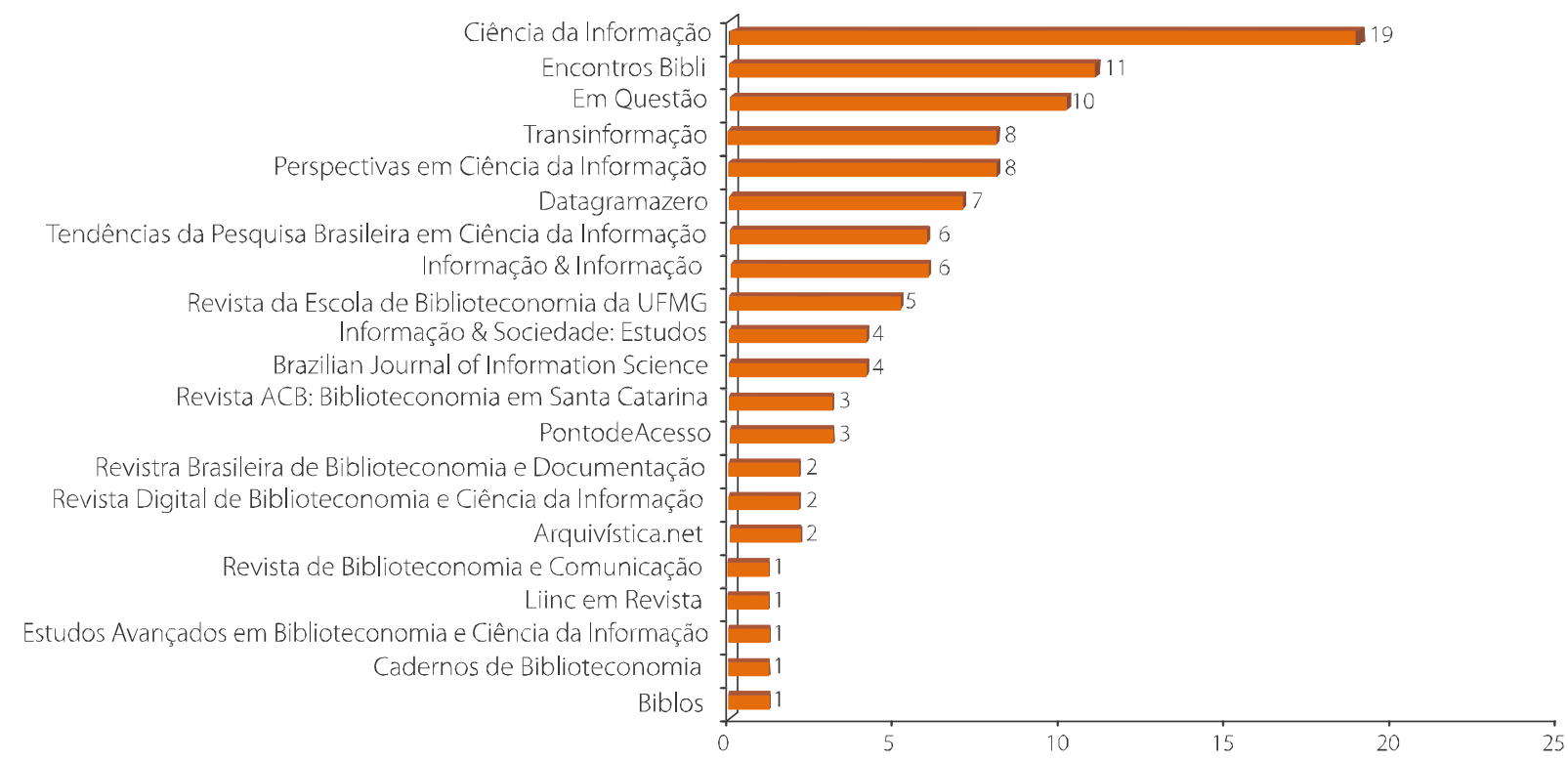

Figura 2. Distribuição da produção científica sobre estudos de citação por periódicos. Fonte: Dados da pesquisa (2015). 
de citação de 1972 a 2014, a Figura 2 exibe as preferências dos autores em relação aos periódicos nacionais.

Os periódicos preferenciais dos autores para publicação de seus trabalhos e relatos foram Ciência da Informação (19 artigos), Encontros Bibli (11 artigos), Em Questão (10 artigos), Transinformação (8 artigos) e Perspectivas em Ciência da Informação (8 artigos), nessa ordem. Os periódicos pontuados publicaram mais da metade dos estudos de citações que compõem o universo da pesquisa (56 artigos), constituindo-se o núcleo da especialidade. A situação pode ser explicada diante na inexistência de um ou mais periódicos voltados para os domínios da Comunicação Científica e Estudos Métricos, ao mesmo tempo que as aplicações previstas pelos estudos de citação podem ser diversas e estarem contempladas em outras propostas de pesquisas. Contudo, as posições alcançadas pelos cinco periódicos, no período de 40 anos, podem defini-los como os mais importantes para a especialidade, pelo fato de concentrar mais de $50 \%$ da produção brasileira.
Os periódicos Datagramazero e Informação \& Informação surgem como veículos importantes para os estudos de citação, tendo em vista a posição alcançada e o tempo de início de suas atividades (final da década de 1990), com potencial para atrair mais trabalhos relacionados. Pelo tempo de início do periódico Tendências da Pesquisa Brasileira em Ciência da Informação em 2008 e pelo foco editorial inicial à publicação de trabalhos de revisão e dos melhores trabalhos indicados pelos GT do Enancib, percebe-se a emergência do mesmo como um importante instrumento de divulgação de pesquisas. Registra-se também a qualidade dos trabalhos publicados pelo periódico, uma vez que foram eleitos pelos membros do GT específico como os melhores, certificando autores e a pesquisa desenvolvida.

Os dados referentes ao intervalo entre as publicações sobre os estudos de citação nesses periódicos expressam níveis de concentração em periódicos ao longo do tempo, conforme o Quadro 3.

Quadro 3. Frequência de publicação por ano nos periódicos brasileiros na temática estudos de citação.

\begin{tabular}{|c|c|c|}
\hline \multirow[t]{2}{*}{ Periódicos } & \multicolumn{2}{|c|}{ Frequência de publicações por ano } \\
\hline & 1973 - 1 publicação & 1992 - 1 publicação \\
\hline & 1974 - 1 publicação & 1994 - 1 publicação \\
\hline & 1975 - 1 publicação & 1996 - 1 publicação \\
\hline & 1976 - 1 publicação & 1998 - 1 publicação \\
\hline \multirow[t]{7}{*}{ Ciência da Informação } & 1982 - 1 publicação & 2001 - 1 publicação \\
\hline & 1983 - 1 publicação & 2006 - 1 publicação \\
\hline & 1984 - 1 publicação & 2007 - 1 publicação \\
\hline & 1986 - 1 publicação & 2008 - 1 publicação \\
\hline & 1990 - 1 publicação & 2010 - 1 publicação \\
\hline & 1991 - 1 publicação & \\
\hline & 2003 - 1 publicação & 2008 - 4 publicações \\
\hline \multirow[t]{3}{*}{ Encontros Bibli } & 2006 - 1 publicação & 2009 - 3 publicações \\
\hline & 2007 - 1 publicação & 2010 - 1 publicação \\
\hline & 2003 - 1 publicação & 2011 - 1 publicação \\
\hline \multirow[t]{3}{*}{ Em Questão } & 2009 - 1 publicação & 2012 - 3 publicações \\
\hline & 2010 - 1 publicação & 2014 - 3 publicações \\
\hline & 1989 - 1 publicação & 2007 - 2 publicações \\
\hline \multirow{4}{*}{ Transinformação } & 1992 - 1 publicação & 2009 - 1 publicação \\
\hline & 1997 - 1 publicação & 2014 - 1 publicação \\
\hline & 2006 - 1 publicação & \\
\hline & 2006 - 1 publicação & 2011 - 2 publicações \\
\hline \multirow[t]{2}{*}{ Perspectivas em Ciência da Informação } & 2008 - 1 publicação & 2013 - 2 publicações \\
\hline & 2009 - 1 publicação & 2014 - 1 publicação \\
\hline
\end{tabular}

Fonte: Dados da pesquisa (2015). 
O Quadro 3 evidencia: (a) o periódico Ciência da Informação como o mais profícuo e com maior regularidade de publicação ao longo dos 40 anos, principalmente nos dois momentos do período embrionário dos estudos de citação no Brasil; (b) os periódicos Encontros Bibli e Em Questão como os mais recorrentes pelos pesquisadores no período emergente, perfazendo juntos vinte e um artigos; (c) a complementaridade de publicação entre os periódicos ao longo dos anos, com aclives (2008 e 2009) e declives (2004 e 2005) acentuados.

Outros tópicos referentes à discussão que podem ter influenciado a presença ou ausência dos trabalhos sobre os estudos de citação no período analisado, dizem respeito à política editorial dos periódicos, ao desenvolvimento das pesquisas e ao interesse dos pesquisadores em divulgar seus trabalhos e os rumos trilhados pelo campo da Ciência da Informação. Os pontos elencados levantam às seguintes indagações: os períodos de declínio de publicação podem ser justificados pela falta de trabalhos submetidos? A pesquisa sobre a temática tem potencial suficiente a ponto de alcançar publicações regulares nos periódicos do campo da Ciência da Informação? Seriam os editores científicos os responsáveis diretos pelo crescimento e declínio dos estudos dessa natureza? Os contextos de pesquisa da especialidade sob a ótica da Ciência da Informação ao longo do tempo não foram prejudicados por políticas e programas científicos?

Quanto ao enfoque teórico dos artigos analisados, chegou-se à seguinte distinção: 102 trabalhos de base teórica normativa, 8 trabalhos de base cognitiva e 2 trabalhos com enfoque sociocultural. A predominância do enfoque teórico normativo é evidente em 40 anos de cobertura temporal. Verificou-se ainda: (a) seis trabalhos categorizados nos enfoques normativo e construtivista; (b) um trabalho classificado nos enfoques normativo e sociocultural; e (c) nenhum trabalho enquadrado nos enfoques construtivista e sociocultural.

Para verticalizar as análises dos trabalhos contemplados na base Brapci, a discussão se pautará nos enfoques teóricos e será conduzida segundo os momentos e períodos dos estudos e as aplicações, das quais se destacam: campos, disciplinas e domínios científicos, instituições e suas unidades, países, periódicos e atores científicos.

\section{Período embrionário dos estudos de citação no Brasil: primeiro momento}

No primeiro momento do período embrionário dos estudos de citação, as contribuições focaram o comportamento das comunidades por meio da produção bibliográfica, centrados na análise das referências arroladas ao final dos trabalhos de campos científicos, tanto de forma generalista (CARVALHO, 1973; PRICE; GURSEY, 1975) como específica: Ciência da Informação (BRAGA, 1973), Ciências Biológicas (CARVALHO, 1976a), Ciências Biomédicas (CARVALHO, 1976b) e Química (CARVALHO, 1975). Outra aplicação encontrada foi um estudo focado em um periódico brasileiro em Física, a fim de identificar os periódicos nacionais e internacionais que compõem o núcleo e a dispersão da disciplina para verificação da existência dos mesmos em uma coleção (GOMES; MARQUES, 1974).

Todos os trabalhos do primeiro momento do período embrionário apresentaram índices de citações, em especial de autores, periódicos e meia vida, com detalhamento preciso dos resultados. Do ponto de vista de concepção e execução, poucos trabalhos registraram explicitamente os objetivos e as justificativas, além de apresentarem detalhamento metodológico precário. Um aspecto importante desse momento é a publicação de duas revisões de literatura sobre os estudos de citação, com reflexões breves, mas amparadas em autores considerados clássicos nos dias de hoje.

\section{Período embrionário dos estudos de citação no Brasil: segundo momento}

O segundo momento do período embrionário é marcado pela retomada da produção e da diversificação de objetos analisados (dissertações, obras literárias, planos de disciplinas). As disciplinas da Biblioteconomia e da Ciência da Informação foram as mais privilegiadas nesse momento dos estudos de citação (RODRIGUES, 1982; FORESTI, 1990; OBERHOFER, 1991; PITTELLA, 1991; OLIVEIRA, 1992; SILVEIRA; BATTISTOTTI, 1996; FREITAS, 1997; BOHN, 2003), com ênfase nos aspectos de distribuição e uso da literatura referenciada em artigos de periódicos, planos de disciplinas e dissertações de mestrado. Desse grupo, destaca-se o trabalho de Oliveira 
(1992) pela proposição e validação de um modelo para verificação da obsolescência de documentos referenciados.

Outros campos e domínios foram contemplados: Agricultura (URBIZAGÁSTEGUI ALVARADO, 1984), Botânica (MELLO, 1996), Ciências Agrárias (TAYLOR \& MATA, 1996), Ciências Agrícolas (VELHO, 1986), Economia (MUELLER, 1999), Educação (FIUZA et al., 1995), Medicina Veterinária (ZIMBA; MUELLER, 2004); Nutrição (OLIVEIRA et al., 1992; DORÉA et al.,1994), Medicina Tropical (GOMES; SANTOS, 2001), Psicologia (WITTER et al., 1989) e Saúde Pública (NORONHA, 1989; 1998). Esses estudos tiveram o propósito de identificar hábitos de citação de autores, aspectos relacionados à idade e cobertura temática das fontes listadas, como também as formas de acesso e uso de coleções de periódicos em bibliotecas, o efeito resultante das autocitações e do fator de impacto, a influência e penetração de determinados autores em periódicos e a relação entre as citações a periódicos e o circuito de publicação para fins de avaliação. Dentre os relatos acima, verificou-se um trabalho relevante para os estudos de citação: a primeira incursão do enfoque teórico construtivista, de natureza aplicada, encontrada nos textos analisados, que investiga os motivos dos cientistas de duas instituições botânicas brasileiras sobre suas preferências em relação aos periódicos e outros itens bibliográficos preferenciais (MELLO, 1996).

As instituições também foram objetos estudados no segundo momento do período embrionário, estando sempre relacionadas a campos científicos, a saber: Ibict (RODRIGUES, 1982), PUC-Campinas (WITTER et al., 1989) e USP (NORONHA, 1989), com foco nas referências de dissertações de programas de pós-graduação distintos, mas com propósitos diferentes. Cinco artigos concernem a pesquisas voltadas aos periódicos científicos de campos científicos distintos, destacando-se os de Lima (1984) por investigar as referências dos artigos do Scientometrics. A contribuição de Torricella Morales et al. (2000) se concentrou na produção cubana recuperada na Web of Science para mensurar o seu impacto global frente aos índices de citação. As referências constantes nas obras do poeta Luiz Delgado foram contempladas no estudo de Pacômio (1982) para revelar as orientações filosóficas e literárias do advogado pernambucano. Os artigos desse conjunto estabeleceram rankings de autores, periódicos e outros itens bibliográficos referenciados, com resultados centrados em elementos bastante explorados no período, tais como autocitações, fator de impacto, frente de pesquisa e idiomas. Contudo, percebeu-se a presença do texto que se diferenciou dos demais como o que discutiu as influências teóricas que circundam a trajetória de uma personalidade artística (PACÔMIO, 1982).

Dentre os destaques do segundo momento dos estudos de citação, traz-se à discussão o trabalho de Motta (1983), sendo a única revisão de literatura sobre os estudos de citação, com reflexões acerca de suas limitações e possibilidades, além de evidenciar as primeiras críticas às generalizações oriundas pelos autores em pesquisas marcadas pelo enfoque normativo. Nesse sentido, tal artigo avança por fazer ponderações, embora breves e não realizadas até então, sobre o panorama dos estudos, sustentadas por revisão bibliográfica pertinente. 0 texto ainda sinaliza os aspectos sociais e psicológicos que circundam cientistas e comunidades, sobretudo às razões das citações, que denominam os objetos de análise do enfoque teórico construtivista dos estudos de citação.

Outro estudo do segundo momento que se evidencia é o de Alvarenga (2003), não somente por trazer os tradicionais índices de citações de autores, mas também por relacioná-los com fatores históricos e políticos do Brasil que marcam a produção dos textos sobre políticas públicas educacionais na Revista Brasileira de Estudos Pedagógicos, configurando-se como a primeira pesquisa de enfoque sociocultural.

O último destaque do segundo momento dos estudos de citação é a revisão de literatura realizada por Vanz e Caregnato (2003), que empreendem uma discussão teórica sobre as práticas de citação e os efeitos sociais e culturais resultantes, sustentada por literatura clássica e pertinente que discrimina as características, os problemas e as potencialidades desses estudos para o universo científico, contemplando os três enfoques teóricos.

Os 27 artigos presentes no segundo momento do período embrionário consolidam o enfoque normativo dos estudos de citação, na medida em que os objetos investigados estão concentrados nas referências dos itens bibliográficos para conhecimento do comportamento de comunidades, apresentação de realidades de campos 
e domínios e outros pontos relacionados à literatura científica. É também nesse momento que se visualizam, em três artigos, os primeiros usos de softwares para organização e manipulação de dados e apresentação de resultados, tais como: CDS-ISIS, Fox Pro 1, e Microsoft Excel e Statistical Package for the Social Sciences (SPSS).

No segundo momento do período embrionário se verificam as primeiras discussões sob o prisma dos enfoques construtivista e sociocultural. Mesmo tímidas, elas sinalizam outras perspectivas de aplicações, não desprezando o repertório teórico e metodológico já desenvolvido e que se consolida nas propostas que se seguem. Contudo, é oportuno mencionar que as descrições metodológicas não acompanham as discussões teóricas e os resultados apresentados nos trabalhos desse período - com registros breves, superficiais e, algumas vezes, equivocados, que buscam expressar o percurso trilhado. Nesse nível de análise, percebe-se um hiato epistemológico dos estudos de citação no segundo momento do período embrionário: avanço teórico e conceitual acerca dos objetos, apresentação e discussão satisfatórias dos resultados alcançados, mas detalhamento metodológico deficiente.

\section{Período emergente dos estudos de citação no Brasil}

O período emergente dos estudos de citação é constituído por 72 trabalhos, que perfazem $70 \%$ do universo da pesquisa e estabelecem momentos significativos de pluralidade teórica e metodológica. Os objetos de análise dos estudos se concentram nas referências contidas nos documentos, apesar de algumas iniciativas direcionadas às citações e às relações entre os contextos de produção e consumo da informação. Dessa forma, destacam-se: a) predominância do enfoque teórico normativo; b) crescimento tímido dos trabalhos com enfoque construtivista; c) ausência de artigos com o enfoque teórico sociocultural; e d) relação entre os enfoques normativo e construtivista.

Dentre os campos e domínios analisados pelos estudos do período emergente, destacam-se: (a) Administração, com 3 artigos (GRAEML et al., 2010; MATTOS; DIAS, 2010; MATTOS; FRAGA, 2010); (b) Biblioteconomia, com 4 artigos (BRAMBILLA; STUMPF, 2006; CAMPELLO et al., 2007; OHIRA; OHIRA, 2008; NASCIMENTO, 2010; (c) Botânica, com um artigo (AMARANTE, 2011); (d) Capital Social, com um artigo (LUCAS; GARCÍA-ZORITA, 2014); (e) Ciência da Informação, com 18 artigos (NASCIMENTO, 2007; NASCIMENTO; BOZO, 2008; PINHEIRO; SILVA, 2008; PINTO; PONTES JÚNIOR, 2008; SILVEIRA; BAZI, 2008a; SILVEIRA; BAZI, 2008b; HYODO, 2009; COSTA; VANZ, 2010; CAREGNATO, 2011; FERNANDES; CENDÓN; ARAÚJO, 2011; OLIVEIRA; GRÁCIO, 2011; VILAN FILHO; ARRUDA; PERUCCHI, 2012; ARANTES; CARELLI, 2013; OLIVEIRA; GRÁCIO, 2013; SANTOS; CORREAA; SILVEIRA, 2013; SILVEIRA et al., 2013; MENEZES; ODDONE, 2014; SILVEIRA; CAREGNATO; BUFREM, 2014); (f) Ciência e Tecnologia, com 4 artigos (VIEIRA; WAINER, 2013; WAINER; VIEIRA, 2013; GRÁCIO; OLIVEIRA, 2014a; GRÁCIO; OLIVEIRA, 2014b); (g) Ciências Contábeis, com um artigo (MENDONÇA NETO; CARDOSO; OYADOMARI, 2011); (h) Competência Informacional, com um artigo (DUDZIAK; 2010); (i) Comunicação, com um artigo (STUMPF; BRANCO, 2010); (j) Comunicação Científica, com um artigo (SILVA; PINHEIRO; REINHEIMER, 2013); (k) Design, com um artigo (COSMOS; SILVEIRA; SILVA, 2013); I) Educação Especial, com um artigo (PIZZANI; SILVA; HAYASHI, 2008); (m) Estudos Métricos da Informação, com 5 artigos (PINTO et al., 2007; URBIZAGÁSTEGUI ALVARADO, 2009; OLIVEIRA; GRÁCIO, 2011b; OLIVEIRA; GRÁCIO, 2012; GRÁCIO; OLIVEIRA, 2014c); (n) Gestão do Conhecimento e Inovação, com um artigo (RODRIGUES; DROESCHER, 2012); (o) Governança Corporativa, com um artigo (LOPES et al., 2013); (p) Odontologia, com um artigo (CENDÓN et al., 2009); (q) Organização e Representação do Conhecimento, com três artigos (ALVARENGA; SILVA, 2010; BUFREM; FREITAS; NASCIMENTO, 2014; FREITAS; NASCIMENTO, BUFREM 2014); (r) Psicologia, com um artigo (JACON, 2007), e (s) Redes Neurais Artificiais, com um artigo (MEIRELES; CENDÓN, 2010).

Os trabalhos desse período são aplicações voltadas para conhecimento das formas de produção, comunicação e utilização da informação científica e tecnológica, por meio de artigos, teses, dissertações e outros itens bibliográficos presentes nas mais diversas bases de dados. Os resultados alcançados nesses textos, em sua maioria, apresentaram índices dos autores citados, da literatura citada, dos periódicos citados, da distribuição geográfica, gerados a partir de bases de dados ad hoc, além dos disponíveis online, como fator de impacto e ín- 
dice $\mathrm{H}$, dentre outros. Muitos resultados baseados em rankings e relações de índices foram ilustrados por meio de representações gráficas proporcionadas pelos recursos tecnológicos das últimas décadas. Também é necessário enfatizar a identificação de estudos comparativos entre os índices ofertados e a proposição de metodologias alternativas para análise dos registros recuperados nas bases de dados online. Por fim, verifica-se a ênfase em pesquisas baseadas na produção científica nacional e internacional, com destaque para o uso do método de análise de redes sociais, destinado a investigar autores e periódicos citados, frentes de pesquisa e grupos de elite, meia vida e idade das citações, autocitações, cocitações e outros aspectos relacionados.

Dos 72 textos cobertos pelo momento de emergência dos estudos de citação, nove deles contemplaram as referências dos artigos veiculados por periódicos, com foco nos aspectos de autoria e frente de pesquisa, idade das citações, literatura citada e cocitações. O periódico Ciência da Informação foi o mais analisado, com seis registros (PINTO et al., 2006; BRESSANE; OHIRA, 2007; LIBERATORE; HERRERO SOLANA; GUIMARÃES, 2007; SILVEIRA; BAZI, 2008a; 2008b; BERNARDINO; CAVALCANTE, 2011), além dos títulos Arquivística.net (PINTO; SANTOS; SANTOS, 2009), Journal of Library and Information Science (SIMISAYE; OSINAIKE, 2010), Memórias do Instituto Oswaldo Cruz (MUGNAINI; EFRAÍN-GARCÍA, 2009) e Scientometrics (MATTOS; JOB, 2008), cada um deles com um registro.

As instituições foram analisadas em nove contribuições no período emergente, concentradas nas formas e possibilidades de avaliação, na geração e organização de indicadores e nas características de produção científica e tecnológica, sendo três delas relacionados a campos científicos. A Universidade Federal do Rio Grande do Sul (UFRGS) foi a instituição mais recorrente (JOB; ALVARENGA, 2008; MATTOS; DIAS, 2010; COSTA; VANZ, 2010; MATTOS; FRAGA, 2010; BRAMBILLA; STUMPF, 2012; NUNEZ; MOURA, 2013), seguida da Associação de Bibliotecários Graduados da República Argentina (LIBERATORE; HERRERO SOLANA; GUIMARÃES, 2006) e da Universidade Federal de Pernambuco (COSMOS; SILVEIRA; SILVA, 2013). Destaca-se ainda o artigo que propõe um modelo de análise multivariada voltada para correção das taxas de autocitações de instituições brasileiras (MARTINS, 2014).
Do conjunto de textos que definem o período emergente dos estudos de citação, pesquisadores também foram objetos de análise em sete trabalhos, a saber: Brenda Dervin (ARAÚJO; PEREIRA; FERNANDES, 2009), Bruno Latour (ARAÚJO, 2009), Carl Ginzburg (JOB, 2007), Carol Kuhlthau (ARAÚJO; BRAGA; VIEIRA, 2010), Frederick Wilfrid Lancaster (ARAÚJO et al., 2009), Jesse Shera (ARAÚJO et al., 2010) e o pesquisador da UFRGS mais citado na Web of Science (BRAMBILLA et al., 2006). Os artigos de Job (2007) e Araújo (2009) são considerados pesquisas de enfoque normativo por trabalharem na perspectiva das referências aos cientistas, com o propósito de evidenciar as contribuições teórico-metodológicas presentes na literatura da área de Ciência da Informação no Brasil. Os trabalhos de Araújo e um grupo de alunos (ARAÚJO et al., 2009; ARAÚJO; PEREIRA; FERNANDES, 2009; ARAÚJO et al., 2010; ARAÚJO; BRAGA; VIEIRA, 2010) contemplam as referências aos pesquisadores presentes na literatura do campo da Ciência da Informação no país e, ainda, a multiplicidade de razões que circundam as citações a esses pesquisadores, arrolando os objetos empíricos dos enfoques normativo e construtivista. No caso do texto de Brambilla, Vanz e Stumpf, o enfoque construtivista ficou evidente, uma vez que as autoras situaram suas atenções nas menções realizadas ao pesquisador a partir de seu artigo mais citado na Web of Science, com a finalidade de expressar não apenas as contribuições da produção do analisado, mas também a repercussão dessa produção. Destaque também para a contribuição de Silveira, Caregnato e Bufrem (2014), que propõem um esquema classificatório das razões das citações, bem como sua aplicação no âmbito das comunicações orais de 2012 e 2013 do GT 7 do Enancib, partindo da ideia de que tais motivos são variados, multidimensionais e simultâneos.

Têm-se ainda os trabalhos que centraram as atenções nos países, voltados para a relação entre autoria e citação no bojo das comparações dos indicadores absolutos e relativos de produção, produtividade e colaboração em nível internacional, perfazendo dois trabalhos com características do enfoque normativo. Os países participantes das discussões realizadas nos artigos foram França e Alemanha (BIGLU, 2006), e Irã e Turquia (BIGLU, 2007).

O período emergente dos estudos de citação não apresentou revisão de literatura ou outra contribuição 
que trouxesse reflexões acerca dos objetos, objetivos e possibilidades dos resultados, além de críticas e situações concretas nos enfoques normativo, construtivista e sociocultural. Entretanto, o trabalho de Silveira e Bazi (2009) apresenta um panorama breve e preciso dos estudos de citações empreendidos no país, com base nas perspectivas quantitativa e qualitativa, como também a ilustração dos problemas encontrados, apontando indicações equivocadas e erradas de citações e referências.

Considera-se que, do ponto de vista instrumental, os estudos de citação do período emergente foram beneficiados pela disponibilidade de dados para recuperação, sobretudo na última década. A recuperação dos dados foi facilitada pelo desenvolvimento tecnológico, que permitiu relacionar as formas de coleta, organização e apresentação dos mesmos, minimizando tempo e esforço no delineamento e execução das pesquisas, a exemplo dos outros períodos. As bases privilegiadas com registro nos trabalhos verificados foram: Biblioteca Digital de Teses e Dissertações do Ibict, Brapci, Dialog, Google Acadêmico, Journal Report Citation, Portal de Periódicos da Capes, SCImago Journal \& Country Rank, Scopus e Web of Science. Mesmo sem a menção nos tópicos esperados nos trabalhos, percebe-se que muitos deles, quando não formataram suas próprias bases, tiveram que importar os dados e reorganizá-los da forma desejada para produzir os resultados que dessem conta dos objetivos. Dentre os softwares apontados nos artigos e relatos pertencentes ao universo do período emergente, têm-se os seguintes: BrOffice, CiteSpace, CorelDraw, CreatePajek, Dataview, EndNote, FlashGet, Microsoft Access, Microsoft Excel, Microsoft Word, NetDraw, Pajek, ProCite, R2, SPSS e Ucinet. No entanto, acredita-se que muitas contribuições não descreveram a utilização dos programas, mesmo fazendo uso de tais instrumentos. A especulação sobre a afirmação se sustenta na grande quantidade de dados trabalhados e nas relações complexas entre eles, nas formas de apresentação dos resultados e de outros detalhes relacionados.

Em virtude do significativo número de trabalhos no período de emergência dos estudos de citação, percebe-se que o enfoque normativo prevalece, enquanto o construtivista tem crescimento tímido, e o sociocultural não é contemplado. Verifica-se que poucos tra- balhos são orientados por problemas de pesquisa, com discussão teórica e conceitual consistente, descrições metodológicas claras e apresentações de resultados que expliquem as realidades e situações investigadas. Constatam-se também algumas propostas teóricas e metodológicas diferenciadas, bem como reflexões críticas dos objetos analisados, conhecimento aprofundado dos instrumentos de coleta e organização e produção de indicadores, sempre centralizados em grupos de pesquisa consolidados. Nota-se que o investimento na técnica de análise de citações é fortemente realizado e talvez, como consequência, se visualizam textos pontuais e repetitivos, que não indicam avanço qualitativo da especialidade.

\section{Considerações finais}

Os estudos de citação no Brasil têm trajetória científica de pouco mais de 40 anos, tendo as primeiras iniciativas sido conduzidas por pesquisadores do campo da Ciência da Informação, com base nas leis bibliométricas. Dos primeiros trabalhos até os dias atuais, no campo da Ciência da Informação no país, a intensidade da produção na temática cresceu substancialmente, sobretudo na última década, com alguns vazios em momentos específicos. Desde os primeiros trabalhos até os mais recentes, os estudos adquiriram maturidade teórica, mas, sobretudo metodológica, alicerçada nas tecnologias de informação que potencializaram não somente o desenvolvimento da técnica, como também a visualização dos resultados.

É oportuno enfatizar que a predominância do enfoque normativo no conjunto de artigos analisados não depõe contra os estudos de citação, na medida em que os estudos realizados consolidaram uma das técnicas de mensuração da informação. A ressalva sobre o tópico recai na ênfase exagerada dos pesquisadores brasileiros em relação aos outros enfoques para complementação do entendimento de outras realidades. Destaca-se também que foi pouco explorada a convivência entre os enfoques teóricos nas pesquisas, sobretudo naquelas que buscavam o maior conhecimento dos contextos de citação. Nesse cenário de possibilidades, acredita-se na complementaridade dos enfoques, de forma a permitir o avanço em outras perspectivas que compreendam a 
citação como um fenômeno social, em detrimento de contribuições pontuais que privilegiam não somente a técnica e a apresentação de resultados eminentemente exploratórios.

Percebe-se que o crescimento do número de trabalhos, a sofisticação dos softwares e das bases de dados e ainda o aumento de pesquisadores e programas de pós-graduação no país não indicaram um avanço epistemológico significativo para os estudos de citação, tendo em vista o percurso trilhado em quarenta anos. Mais que isso, a situação pode expressar um efeito reprodutivo, que limita a capacidade criativa para incursão em outras perspectivas, como também a cristalização das concepções dos trabalhos, das trajetórias metodológicas e das análises dos resultados. Contudo, pondera-se em duas frentes: a) será que o tempo percorrido pelos estudos de citação ainda não foi suficiente para o salto epistemológico almejado?; b) quais as estratégias e possibilidades necessárias para atingir os patamares desejados em relação às pesquisas a serem desenvolvidas nos próximos anos?

Quanto ao futuro, embora seja arriscado fazer previsões acerca do tema, espera-se que as pesquisas no cenário nacional, antes de tudo, dimensionem, em suas propostas, as citações e as referências como fenômenos do contexto científico. Além disso, é necessário ousadia e criatividade nas formas de compreensão dos fenômenos e objetos a serem estudados, bem como maior rigor e aprofundamento nas discussões teóricas e, principalmente, nas descrições metodológicas.

As perspectivas de estudos para os próximos anos, com base na tendência internacional, devem se voltar para: a) os efeitos dos índices de citação na produção científica brasileira e estrangeira em nível comparativo; b) a repercussão dos indicadores de citação nas políticas nacionais de ciência e tecnologia e avaliação e gestão da pesquisa e pós-graduação; c) os estudos dos hábitos e motivos de citação de pesquisadores e comunidades científicas e seus impactos nos estudos de avaliação da ciência; d) a emergência e distinção entre os indicadores tradicionais e alternativos de citação, em especial os relacionados às redes sociais; e) os aspectos sociais e ideológicos dos contextos de citação entre pesquisadores, comunidades e campos científicos; f) a proposição de instrumentos metodológicos para mensuração do impacto das citações em diferentes contextos científicos.

\section{Colaboradores}

Todos os autores contribuíram em todas as etapas do artigo.

\section{Referências}

ALVARENGA, L. Política editorial e Estado: estudo bibliométrico de artigos publicados na Revista Brasileira de Estudos Pedagógicos, 1944-74. Informação \& Sociedade: Estudos, v. 13, n. 1, p. 77-120, 2003.

ALVARENGA, L.; SILVA, D. L. Organização e representação do conhecimento na ciência da informação: revisão da literatura. Tendências da Pesquisa Brasileira em Ciência da Informação, v. 3, n. 1, p. 47-84, 2010.

AMARANTE, C. Professores/pesquisadores da Pós-graduação em Botânica no Brasil: análises métricas de produtividade. Tendências da Pesquisa Brasileira em Ciência da Informação, v. 4, n. 1, 2011. Disponível em: <http://ridi.ibict.br/handle/ 123456789/754>. Acesso em: 12 fev. 2015.

ARANTES, F. M.; CARELLI, A. E. A temática recepção na revista Ciência da Informação: estudo da produção. Informação \& Informação, v. 18, n. 2, p. 20-36, 2013.

ARAÚJO, C. A. A. et al. A contribuição de F.W. Lancaster para a Ciência da Informação no Brasil. Ponto de Acesso, v. 3, n. 2, p. 132-146, 2009.

ARAÚJO, C. A. A. et al. A contribuição de J.H. Shera para a Ciência da Informação no Brasil. Revista ACB: Biblioteconomia em Santa Catarina, v. 15, n. 2, p. 71-89, 2010.

ARAÚJO, C. A. A.; BRAGA, R. M. O.; VIEIRA, W. O. A contribuição de C. Kuhlthau para a Ciência da Informação no Brasil. Revista Digital de Biblioteconomia e Ciência da Informação, v.7, n.2, p.185-198, 2010. Disponível em: <http://periodicos.sbu. unicamp.br/ojs/index.php/rdbci/article/view/1963>. Acesso em: 12 fev. 2015.

ARAÚJO, C. A. A.; PEREIRA, G. A.; FERNANDES, J. R. A contribuição de B. Dervin para a Ciência da Informação no Brasil. Encontros Bibli, v. 14, n. 28, p. 57-72, 2009.

ARAÚJO, R. F. Leituras de Bruno Latour na Ciência da Informação: analisando citações. Ponto de Acesso, v. 3, n. 3, p. 299-316, 2009.

BARRETO, A. A.; MIRANDA, A. Pesquisa em Ciência da Informação no Brasil: síntese e perspectiva. Datagramazero, v. 1, n. 6, 2000. Disponível em: <http://www.brapci.ufpr.br/brapci/ index.php/article/download/7431>. Acesso em: 12 fev. 2015. 
BERNARDINO, M. C. R.; CAVALCANTE, R. S. Análise de citações dos artigos da revista Ciência da Informação no período de 2000 a 2009. Em Questão, v. 17, n. 1, p. 247-263, 2011.

BIGLU, M. H. Tendency towards the self-citation among journals in Iran and Turkey. Arquivística.net, v.3, n.2, p.1-8, 2007. Available from: <http://eprints.rclis.org/10733/>. Acesso em: 12 fev. 2015

BIGLU, M. H. The comparison of impact factor and self citation trend between French and German journals. Arquivística.net, v. 2 , n. 2 , p. 143-156, 2006. Available from: <http://eprints. rclis.org/10477>. Cited: 12 fev. 2015.

BOHN, M. C. R. Autores e autoria em periódicos brasileiros em Ciência da Informação. Encontros Bibli, n. 16, p. 1-19, 2003.

BORNMANN, L.; DANIEL, H. D. What do citation counts measure? A review of studies on citing behavior. Journal of Documentation, v. 64, n. 1, p. 45-79, 2008.

BRAGA, G. M. Relações bibliométricas entre a frente de pesquisa (research front) e revisões de literatura: estudo aplicado a Ciência da Informação. Ciência da Informação, v. 2, n. 1, p. 9-26, 1973.

BRAMBILLA, S. D. S.; STUMPF, I. R. C. Artigos da UFRGS na Web of Science: os mais citados e seus citantes. Em Questão, v. 18, ed. esp., p. 179-197, 2012.

BRAMBILLA, S.D. S.; STUMPF, I. R. C. Planos de ensino do Curso de Biblioteconomia da Universidade Federal do Rio Grande do Sul: estudo bibliométrico de referências. Transinformação, v. 18, n. 1, p. 37-47, 2006.

BRAMBILLA, S. D. S.;VANZ, S. A. S.;STUMPF, I. R. C. Mapeamento de um artigo produzido na UFRGS: razões das citações recebidas. Encontros Bibli, n. esp., p. 195-208, 2006.

BRESSANE, J. M.; OHIRA, M. L. B. Evolução e avaliação da Revista ACB: Biblioteconomia em Santa Catarina enquanto fonte de pesquisa (2000-2004). Revista ACB: Biblioteconomia em Santa Catarina, v. 12, n. 1, p. 5-26, 2007.

BUFREM, L. S.; FREITAS, J. L.; NASCIMENTO, B. S. Autoria e pesquisa em Organização e Representação do Conhecimento: análise da produção científica em Ciência da Informação. Em Questão, v. 20, n. 3, ed. esp., p. 150-165, 2014.

CAMPELLO, B. S. et al. Literatura sobre biblioteca escolar: características de citações de teses e dissertações brasileiras. Transinformação, v. 19, n. 3, p. 227-236, 2007.

CAREGNATO, S. E. Google Acadêmico como ferramenta para os estudos de citação: avaliação da precisão pelas buscas por autor. Ponto de Acesso, v. 5, n. 3, p. 72-86, 2011.

CARVALHO, M. L. B. Análise de citações da literatura biomédica: uma revisão da literatura de 1972 a 1975. Revista da Escola de Biblioteconomia da UFMG, v. 5, n. 2, p. 195-204, 1976 b.

CARVALHO, M. L. B. Estudo de citações da literatura produzida pelos professores do Instituto de Ciências Biológicas da UFMG. Ciência da Informação, v. 5, n. 1/2, p. 27-42, 1976a.

CARVALHO, M. L. B. Índice de citações: uma revisão de literatura. Revista da Escola de Biblioteconomia da UFMG, v. 2, n. 2 , p. 207-217, 1973

CARVALHO, M. M. Análises bibliométricas da literatura de Química no Brasil. Ciência da Informação, v. 4, n. 2, p. 119-141, 1975
CENDÓN, B. V. et al. Uso dos periódicos do Portal Capes pelos Programas de Pós-Graduação da Faculdade de Odontologia de Araraquara - UNESP - no período de 2000 a 2005. Transinformação, v. 21, n. 2, p. 133-149, 2009.

COSMOS, M. R. P.; SILVEIRA, M. A. A.; SILVA, F. M. Fontes de informação digitais: análise das dissertações do Programa de Pós-Graduação em Design da UFPE. Informação \& Informação, v. 18, n. 3, p. 114-137, 2013.

COSTA, J. G.; VANZ, S. A. S. A produção intelectual em Ciência da Informação: análise de citações do DCI/UFRGS de 2000 a 2008. Em Questão, v. 16, n. 1, p. 79-93, 2010.

DAVIS, P. M. Reward or persuasion? The battle to define the meaning of a citation. Learned Publishing, v.22, p.5-11, 2009.

DÓREA, J. G.; OLIVEIRA, A. C.; DOMENE, S. M. A. Qualidade da pesquisa científica em Nutrição no Brasil: 1986-1990. Ciência da Informação, v. 23, n. 2, p. 264-268, 1994.

DUDZIAK, E. A. Competência informacional: análise evolucionária das tendências da pesquisa e produtividade científica em âmbito mundial. Informação \& Informação, v. 15, n. 2, p. 1-22, 2010.

ERIKSON, M. G.; ERLANDSON, P. A taxonomy of motives to city. Social Studies of Science, v. 44, n. 1, p. 1-13, 2014.

FERNANDES, W. R.; CENDÓN, B. V.; ARAÚJO, C. A. A. Information Science and its correlated areas: A case study at the Federal University of Minas Gerais. Brazilian Journal of Information Science, v. 5, n. 1, p. 3-35, 2011.

FIUZA, M. M.; DRUMMOND, V. R. P.; PITTELLA, M. C. Influência de autores franceses na literatura de Educação no Brasil. Revista da Escola de Biblioteconomia da UFMG, v. 24, n. 1, p. 35-51, 1995.

FORESTI, N. A. B. Contribuição das revistas brasileiras de Biblioteconomia e Ciência da Informação enquanto fonte de referência para a pesquisa. Ciência da Informação, v. 19, n. 1, p. 53-71, 1990.

FREITAS, J. L.; NASCIMENTO, B. S.; BUFREM, L. S. A Organização do Conhecimento na dinâmica da pesquisa em artigos da literatura científica da BRAPCI. Transinformação, v. 26, n. 3, p. 295-303, 2014.

FREITAS, M. H. A. Oito anos de Transinformação. Transinformação, v. 9, n. 3, p. 120-134, 1997.

GLANZEL, W. Bibliometrics as a research field: A course on theory and application of bibliometric indicators. Course Handouts, 2003. Available from: <http://nsdl.niscair.res.in/ jspui/bitstream/123456789/968/1/Bib_Module_KUL.pdf>. Cited: Sept. 12, 2014.

GOMES, S.P.; SANTOS, M. A. L. C. Avaliação de um periódico na área de Medicina Tropical. Ciência da Informação, v. 30, n. 2, p. 91-100, 2001.

GOMES, T. F.; MARQUES, A. Seleção de periódicos para a área de Física. Ciência da Informação, v. 3, n. 2, p. 105-146, 1974.

GRÁCIO, M. C. C.; OLIVEIRA, E. F. T. Análise de cocitação de autores: um estudo teórico-metodológico dos indicadores de proximidade, aplicados ao GT7 da ANCIB. Liinc em Revista, v. 9, n. 1, p. 196-213, 2013. 
GRÁCIO, M. C. C.; OLIVEIRA, E. F. T. Estudo comparativo teórico metodológico dos índices normalizados de citação: uma aplicação na ciência brasileira (1996-2007). Em Questão, v. 20, n. 3, ed. esp., p. 8-26, 2014a.

GRÁCIO, M. C. C.; OLIVEIRA, E. F. T. Estudos de análise de cocitação de autores: uma abordagem teórico-metodológica para a compreensão de um domínio. Tendências da Pesquisa Brasileira em Ciência da Informação, v.7, n. 1, 2014c. Disponível em: <http://inseer.ibict.br/ancib/index.php/tpbci/article/ viewArticle/137>. Acesso em: 12 fev. 2015

GRÁCIO, M. C. C.; OLIVEIRA, E. F. T. Indicadores cientométricos normalizados: um estudo na produção científica brasileira internacional. Perspectivas em Ciência da Informação, v. 19, n. 3, p. 118-133, 2014b.

GRAEML, A. R. et al. Redes sociais e intelectuais em Administração da Informação: uma análise cientométrica do período 1997-2006. Informação \& Sociedade: Estudos, v. 20, n. 1, p. 95-110, 2010.

HYODO, T. A literatura sobre necessidades de informação: uma análise a partir de artigos publicados no periódico "Ciência da Informação". Encontros Bibli, v. 14, n. 27, p. 135-145, 2009.

JACON, M. C. M. Base Qualis e a indução do uso de periódicos da área de Psicologia. Transinformação, v. 19, n. 2, p. 189-197, 2007.

JOB, I. Textos científicos em Ciência da Informação e Ginzburg: uma vinculação possível. Encontros Bibli, n. 24, p. 139-151, 2007.

JOB, I.; ALVARENGA, L. Citações presentes em teses e perfis de pesquisadores: fontes de indícios para se estudar a área de Educação Física. Perspectivas em Ciência da Informação, v. 13, n. 3, p. 151-166, 2008.

LIBERATORE, G. HERRERO SOLANA, V.; GUIMARÃES, J. A. C. Análise bibliométrica do periódico brasileiro Ciência da Informação durante o período 2000-2004. Brazilian Journal of Information Science, v. 1, n. 2, p. 3-21, 2007.

LIBERATORE, G.; HERRERO SOLANA, V. Panorama da Biblioteconomia e Documentação na Argentina: análise das atas da Associação de Bibliotecários Graduados da República Argentina (ABGRA) 1990-2001. Perspectivas em Ciência da Informação, v. 11, n. 2, p. 255-266, 2006.

LIMA, R.C.M. Estudo bibliométrico: análise de citações no periódico "Scientometrics". Ciência da Informação, v. 13, n. 1 , p. $57-66,1984$

LOPES, E. C. et al. A construção do conhecimento sobre Governança Corporativa: uma análise bibliométrica. Datagramazero, v. 14, n. 2, 2013. Disponível em: <http://www.dgz.org.br/abr13/ Art_05.htm>. Acesso em: 12 fev. 2015.

LUCAS, E. O.; GARCIA-ZORITA, J. C. Produção científica sobre Capital Social: um estudo por acoplamento bibliográfico. Em Questão, v. 20, n. 3, ed. esp., p. 27-42, 2014

MARTINS, D. L. Uso da análise multivariada para mapeamento do perfil de internacionalização das universidades federais brasileiras: um estudo exploratório a partir de dados disponíveis na base Web of Science. Em Questão, v. 20, n. 3, ed. esp., p. 61-72, 2014.
MATTOS, A. M.; DIAS, E. W. Periódicos eletrônicos sobre Administração disponíveis no Portal de Periódicos da Coordenação de Aperfeiçoamento de Pessoal de Nível Superior: uma avaliação. Ciência da Informação, v. 39, n. 1, p. 51-66, 2010.

MATTOS, A. M.; FRAGA, T. M. A. Utilizando a análise de citações de teses para avaliar a coleção de livros em bibliotecas universitárias. Encontros Bibli, v. 15, n. 29, p. 106-125, 2010.

MATTOS, A. M.; JOB, I. A produção científica brasileira no periódico Scientometrics de 1978 até 2006. Encontros Bibli, v. 13, n. 26, p. 47-61, 2008 .

MEIRELES, M. R. G.; CENDÓN, B. V. Aplicação prática dos processos de análise de conteúdo e de análise de citações em artigos relacionados às redes neurais artificiais. Informação \& Informação, v. 15, n. 2, p. 76-92, 2010.

MELLO, P. M. A. C. A citação bibliográfica no contexto da comunicação: um estudo exploratório na área de Botânica. Ciência da Informação, v. 25, n. 3, 1996.

MENDONÇA NETO, O. R.; CARDOSO, R. L.; OYADOMARI, J. C. T. Os periódicos de maior impacto na pesquisa contábil brasileira e norte-americana: uma análise comparativa baseada nas citações em teses de doutorado. Perspectivas em Ciência da Informação, v. 16, n. 3, p. 93-115, 2011.

MENEZES, V. S.; ODDONE, N. Os livros nas teses em Ciência da Informação: um estudo de citação (2007-2009). Tendências da Pesquisa Brasileira em Ciência da Informação, v.7, n. 1, 2014. Disponível em: <http://inseer.ibict.br/ancib/index.php/tpbci/ article/view/138>. Acesso em: 12 fev. 2015.

MOTTA, D. F. Validade da análise de citação como indicador de qualidade da produção científica: uma revisão. Ciência da Informação, v. 12, n. 1, p. 53-59, 1983.

MUELLER, S. P. M. O círculo vicioso que prende os periódicos nacionais. Datagramazero, n.0, 1999. Disponível em: <http:// www.dgz.org.br/dez99/F_I_art.htm>. Acesso em: 12 fev. 2015.

MUGNAINI, R.; EFRAÍN-GARCIA, P. Influências metodológicas na mensuração de impacto: o caso das Memórias do Instituto Oswaldo Cruz e sua "qualificação". Perspectivas em Ciência da Informação, v. 14, n. 3, p. 179-189, 2009.

NASCIMENTO, M. J. Planos de ensino de "usuários da informação" nos cursos de Biblioteconomia no Brasil. Datagramazero, v. 10, n. 1, 2010. Disponível em: <http://basessibi.c3sl.ufpr.br/ brapci/v/a/8344>. Acesso em: 12 fev. 2015.

NASCIMENTO, M. J. Presença e visibilidade da literatura hispanófona em quatro revistas brasileiras de Biblioteconomia, Documentação e Ciência da Informação: análise de citação. Ciência da Informação, v. 36, n. 3, p. 29-38, 2007.

NASCIMENTO, M. J.; BOSO, A. K. Presença da literatura hispanófona em revistas eletrônicas brasileiras de Biblioteconomia e Ciência da Informação. Encontros Bibli, v. 13, n. 26, p. 62-77, 2008

NICOLAISEN, J. Citation analysis. Annual Review of Information Science and Technology, v. 41, p. 609-641, 2007.

NORONHA, D.P. Análise das citações das dissertações de mestrado e teses de doutorado em Saúde Pública (1990-1994): estudo exploratório. Ciência da Informação, v. 27, n. 1, p. 66-75, 1998. 
NORONHA, D.P. Utilização de periódicos por docentes e alunos de pós-graduação de uma instituição de ensino e pesquisa em Saúde Pública. Revista Brasileira de Biblioteconomia e Documentação, v. 2, n. 3/4, p. 68-95, 1989.

NUNEZ, Z. A. G.; MOURA, A. M. M. Análise de citações na área de Comunicação e Informação: o caso de um programa de pós-graduação. Revista Digital de Biblioteconomia e Ciência da Informação, v.11, n.2, p.40-60, 2013. Disponível em: <http:// periodicos.sbu.unicamp.br/ojs/index.php/rdbci/article/view/ 1637>. Acesso em: 12 fev. 2015

OBERHOFER, C. M. A. Valor da informação: percepção versus quantificação. Ciência da Informação, v. 20, n. 2, p. 119-129, 1991.

OHIRA, M. L. B.; OHIRA, M. Seminário Nacional de Bibliotecas Universitárias - SNBU (2000-2004): análise de citações. Encontros Bibli, v. 13, n. 25, p. 136-155, 2008.

OLIVEIRA, A. C.; DÓREA, J. G.; DOMENE, S. M. A. Bibliometria na avaliação da produção científica da área de Nutrição registrada no Cibran: período de 1984-1989. Ciência da Informação, v. 21 , n. 3, p. 239-242, 1992

OLIVEIRA, E. F. T.; GRÁCIO, M. C. C. Indicadores bibliométricos em Ciência da Informação: análise dos pesquisadores mais produtivos no tema Estudos Métricos na base Scopus. Perspectivas em Ciência da Informação, v. 16, n. 4, p. 16-28, $2011 \mathrm{~b}$.

OLIVEIRA, E. F. T.; GRÁCIO, M. C. C. Visibilidade dos pesquisadores no GT7 da ANCIB: um estudo de cocitações. Tendências da Pesquisa Brasileira em Ciência da Informação, v. 4, n. 1, 2011 a. Disponível em: <http://inseer.ibict.br/ancib/index.php/tpbci/ article/viewFile/51/88>. Acesso em: 12 fev. 2015.

OLIVEIRA, E. F. T.; GRÁCIO, M. C. C. Visibilidade dos pesquisadores no periódico Scientometrics a partir da perspectiva brasileira: um estudo de cocitação. Em Questão, v. 18, ed. esp., p. 99-113, 2012.

OLIVEIRA, S. M. The reliability of two citation cheking technique measurement instruments. Transinformação, v. 4, n. 1/3, p. 55-79, 1992.

PACÔMIO, M. T. A. Bibliografia de autores pernambucanos - Luiz Delgado: um estudo de citações. Cadernos de Biblioteconomia, n. 5, p. 28-37, 1982.

PINHEIRO, L. V.; SILVA, E. L. As redes cognitivas na Ciência da Informação brasileira: um estudo nos artigos científicos publicados nos periódicos da área. Ciência da Informação, v. 37, n. 3, p. 38-50, 2008.

PINTO, A. L. et al. Scientific indicators on literature in bibliometric and scientometric through social networks. Brazilian Journal of Information Science, v. 1, n. 1, p. 55-73, 2007.

PINTO, A. L.: PONTES JÚNIOR, J. Índice científico da Ciência da Informação: comparativo dos autores com maior visibilidade no ISI e no Google Acadêmico. Informação \& Informação, v. 13, n. 1, p. 1-14, 2008.

PINTO, A. L.; RODRÍGUEZ BARQUÍN, B. A.; MOREIRO GONZÁLEZ J. A. Análisis de citación de la revista Ciência da Informação del IBICT. Ciência da Informação, v. 35, n. 3, p. 153-165, 2006.

PINTO, M. D. S.: SANTOS, R. N. M.: SANTOS, E. M. B. Análise de citação da revista eletrônica Arquivística.net: uma aplicação das técnicas bibliométricas. Em Questão, v. 15, n. 1, p. 27-42, 2009.

PITTELLA, M. C. Análise de citação de periódicos brasileiros de Biblioteconomia 1972-1982. Revista da Escola de Biblioteconomia da UFMG, v. 20, n. 2, p. 191-217, 1991.

PIZZANI, L.; SILVA, R. C.; HAYASHI, M. C. P. I. Bases de dados e bibliometria: a presença da educação especial na base Medline. Revista Brasileira de Biblioteconomia e Documentação, Nova Série, v. 4, n. 1, p. 68-85, 2008.

PRICE, D. S.; GÜRSEY, S. Studies in scientometrics II:The relation between source author and cited author populations. Ciência da Informação, v. 4, n. 2, p. 103-108, 1975.

RODRIGUES, C. R.; DROESCHER, F. D. Estudo da produção científica em Gestão do Conhecimento e Inovação identificada na Biblioteca Digital de Teses e Dissertações (BDTD). Biblos, v. 26, n. 2, p. 9-29, 2012.

RODRIGUES, M. P. L. Citações nas dissertações de mestrado em Ciência da Informação. Ciência da Informação, v. 11, n. 1, p. 35-61, 1982

SANTOS, M. T.; CORRÊA, R. F.; SILVEIRA, M. A. A. Estudos brasileiros sobre Ontologia na Ciência da Informação. Datagramazero, v.14, n.1, 2013. Disponível em: <http:// www.dgz.org.br/fev13/Art_05.htm>. Acesso em: 12 fev. 2015.

SILVA, E. L.; PINHEIRO, L. V.; REINHEIMER, F. M. Redes de conhecimento em artigos de comunicação científica: estudo baseado em citações bibliográficas de artigos de periódicos na área de Ciência da Informação no Brasil. Informação \& Sociedade: Estudos, v. 23, n. 1, p. 145-160, 2013.

SILVEIRA, A.; BATTISTOTTI, Z. H. M. Marketing nos currículos plenos dos Cursos de Biblioteconomia da Região Sul do Brasil. Revista ACB: Biblioteconomia em Santa Catarina, v. 1, n. 1, p. 55-67, 1996.

SILVEIRA, M. A. A. et al. Domínios científicos da Ciência da Informação representados no GT7 do ENANCIB: análise das citações (2007-2012). Tendências da Pesquisa Brasileira em Ciência da Informação, v. 6, n. 2, 2013. Disponível em: <http:// inseer.ibict.br/ancib/index.php/tpbci/article/viewArticle/ 111>. Acesso em: 12 fev. 2015.

SILVEIRA, M. A. A.; BAZI, R. E. R. A Ciência da Informação no Brasil e sua frente de pesquisa: estudo cienciométrico sob a ótica da institucionalização da pesquisa científica (1995-2005). Encontros Bibli, v. 13, n. 26, p. 1-16, 2008a.

SILVEIRA, M. A. A.; BAZI, R. E. R. As referências nos estudos de citação apontamentos para uma discussão. Datagramazero, v. 10, n. 4, 2009. Disponível em: <http://basessibi.c3sl.ufpr.br/ brapci/v/a/8249>. Acesso em: 12 fev. 2015.

SILVEIRA, M. A. A.; BAZI, R. E. R. Rede de textos científicos na Ciência da Informação: análise cienciométrica da institucionalização de um campo científico. Datagramazero, v. 9, n. 3 , 2008b. Disponível em: <http://basessibi.c3sl.ufpr.br/brapci/ index.php/article/download/7617>. Acesso em: 12 fev. 2015.

SILVEIRA, M. A. A.; CAREGNATO, S. E.; BUFREM, L. S. Estudo das razões das citações na Ciência da Informação: proposta de classificação. Tendências da Pesquisa Brasileira em Ciência da Informação, v. 7, n. 2, 2014. Disponível em: <http://inseer. ibict.br/ancib/index.php/tpbci/article/viewArticle/163>. Acesso em: 12 fev. 2015 
SIMISAYE, A. O.; OSINAIKE, A. B. Análise de citação de periódicos de Biblioteconomia e Ciência da Informação (2004-2009). Brazilian Journal of Information Science, v. 4, n. 1, p. 37-63, 2010.

STUMPF, I. R. C.; BRANCO, Z. S. Análise de citações dos artigos da Intercom - Revista Brasileira de Ciências da Comunicação. Informação \& Informação, v. 15, n. esp., p. 94-110, 2010.

TAYLOR, M. W.; MATA, M. M. S. Bibliografia básica das disciplinas dos currículos das escolas agrotécnicas. Revista de Biblioteconomia e Comunicação, v. 7, p. 38-49, 1996.

TORRICELLA MORALES, R. G.; HOOYDONK, G.; ARAÚJO RUIZ, J. A. Estudio bibliométrico sobre la presencia de los autores cubanos en el Web of Science. Datagramazero, v. 1, n. 4, 2000 Disponible em: <http://basessibi.c3sl.ufpr.br/brapci/index. php/article/download/7422>. Acceso: 12 feb. 2015.

URBIZAGÁSTEGUI ALVARADO, R. A frente de pesquisa na literatura sobre produz tividade de autores. Encontros Bibli, v. 14, n. 28, p. $38-56,2009$

URBIZAGÁSTEGUI ALVARADO. R. Análise das fontes de informação bibliográficas citadas no periódico "Pesquisa Agropecuária Brasileira". Estudos Avançados em Biblioteconomia, v. 3, p. 167-189, 1984

VANZ, S. A. S.; CAREGNATO, S. E. Estudos de citação: uma ferramenta para entender a comunicação científica. Em Questão, v. 9, n. 2, p. 295-307, 2003.
VELHO, L. M. L. S. A contemporaneidade da pesquisa agrícola brasileira como reflexo da distribuição da idade das citações. Ciência da Informação, v. 15, n. 1, p. 3-9, 1986.

VIEIRA, P. V. M.; WAINER, J. Correlações entre a contagem de citações de pesquisadores brasileiros, usando o Web of Science, Scopus e Scholar. Perspectivas em Ciência da Informação, v. 18, n. 3, p. 15-60, 2013.

VILAN FILHO, J. L.; ARRUDA, R. V.; PERUCCHI, V. Análise das citações aos periódicos científicos brasileiros das áreas de informação. Em Questão, v. 18, ed. esp., p. 115-127, 2012.

WAINER, J.; VIEIRA, P. Avaliação de bolsas de produtividade em pesquisa do CNPq e medidas bibliométricas: correlações para todas as grandes áreas. Perspectivas em Ciência da Informação, v. 18, n. 2, p. 60-78, 2013.

WITTER, G. P. et al. As referências bibliográficas nas dissertações de mestrado em Psicologia Clínica da PUCCAMP (1972-1987). Transinformação, v. 1, n. 2, p. 205-217, 1989.

WOUTERS, P. The citation culture. 1999. Thesis (Doctorate in Science) - Faculty of Sciences, University of Amsterdan, Amsterdan, 1999

ZIMBA, H. F.; Mueller, S.M.P. Colaboração internacional e visibilidade científica de países em desenvolvimento: o caso da pesquisa na área de Medicina Veterinária em Moçambique. Informação \& Sociedade: Estudos, v. 14, n. 1, p. 45-68, 2004. 
